\title{
EFFECTIVE LENGTH FACTOR OF COLUMNS IN NON-SWAY MODULAR STEEL BUILDINGS
}

\author{
Guo-Qiang $\mathrm{Li}^{1,2}, \mathrm{Ke} \mathrm{Cao}^{1}$, Ye $\mathrm{Lu}^{1,2,{ }^{*}}$ and Jian Jiang ${ }^{1}$ \\ ${ }^{I}$ College of Civil Engineering, Tongji University, Shanghai 200092, PR China \\ ${ }^{2}$ State Key Laboratory for Disaster Reduction in Civil Engineering, Tongji University, Shanghai 200092, PR China \\ *(Corresponding author: E-mail: luyet@tongji.edu.cn)
}

Received: 8 February 2016; Revised: 27 January 2017; Accepted: 25 February 2017

\begin{abstract}
Prefabrication by off-site manufacturing (OSM) leads to faster construction, improved quality, and reduced resources and waste. As a specific type of off-site structure, modular steel buildings consisting of volumetric modular units is a relatively new structural form in comparison with traditional steel frames with fixed or flexible beam-to-column connections. For multi-strorey modular steel buildings, additional lateral force-resisting systems are commonly used to prevent the structural side sway. In order to rationally evaluate the stability of columns in the non-sway modular steel buildings, the governing equations for determining the effective length factor ( $K$-factor) of columns are derived using the three-column sub-assemblage model. A simplified method based on the French rule is proposed to determine $K$-factors. Its accuracy and effectiveness are verified against governing equations (maximum error within $6 \%$ ) and finite element simulation of a six-storey modular steel frame (maximum error within $9 \%$ ). The influencing factors on the $K$-factor are studied. The results show that the available methods such as the alignment chart and French rule cannot be directly applied to determine $K$-factors for the modular steel buildings. It is found that the boundary restraint parameters and their relative values affect the $K$-factor. The assumption of pinned connections between modular units is found to be non-conservative. It is recommended to check and strengthen the flexible connections for the design of modular steel buildings with too small or too large relative stiffness of the connections between modules.
\end{abstract}

Keywords: Effective length factor, column buckling, semi-rigid connection, non-sway modular steel building, simplified method

DOI: $10.18057 /$ IJASC.2017.13.4.6

\section{INTRODUCTION}

Modules, as prefabricated room-sized volumetric units are normally fully fitted at the manufacturing stage and are installed on site as load-bearing 'building blocks' [1]. Although the modular concept is similar to temporary and mobile buildings, it differs in terms of structural design and quality requirements. A multi-storey modular steel building consisting of volumetric modular units (hereinafter, modular steel building) is a collection of modular units joined together to form a self-supported and load-bearing structure. It has to conform to building codes for its intended use [2]. There are two generic forms of modular units as shown in Figure1, respectively. One is continuously supported modules where vertical loads are transferred through walls (Figure1a). The other is corner-supported modules where vertical loads are transferred through columns (Figure1b) [3]. This study focuses on corner-supported modules.

In most current building codes for steel members and frames, the design of columns is based on the evaluation of elastic restraints at both ends of columns, from which the effective length factor (hereinafter, the $K$-factor) is derived for estimating the buckling load. The alignment chart method was used in codes of the United States [4] and Canada [5] to obtain $K$-factors. It is the graphic solution of mathematically exact equations. The accuracy of alignment charts essentially depends on the chart size of and users' sharpness of vision. In Europe [6] and China [7], the $K$-factor can be determined by simplified equations called "French rules" [8]. These equations are accurate, yet 
simple enough to be used. However, both of these two methods are proposed based on traditional steel frames with fixed beam-to-column connections.

Many efforts have been taken to determine the $K$-factor for flexibly connected non-sway frames. Three data bases have been made for connection models by Goverdhan[9]; Nethercot[10]; and Kishi-Chen[11]. For non-sway frames with flexible connections, Chen[12], Lui [13], and Bjorhovde [14] proposed calculation methods of $K$-factors. Lui [13] proposed a simple procedure in which the initial and zero connection stiffness were taken for unloading and loading conditions, respectively. It was the simplest method but failed to consider the non-linearity of beam-to-column connections for both braced and unbraced frames [12]. Barakat and Chen[12] recommended the modification of the relative stiffness factor in the alignment chart method using the secant connection stiffness. For non-sway frames, it led to a constant $K$-factor at all loading levels which was similar to Lui's method.

For modular steel buildings, the modular units are produced in a factory with welded beam-to-column connections, and are then assembled on site using bolt connections. Thus, the connection can be considered as semi-rigid consisting of rigid individual modular unit.. For multi-strorey or high-rise modular steel buildings, additional lateral force-resisting systems such as braces[15] or steel panels[16] are commonly used to effectively prevent their lateral sway. The models for traditional braced frames with flexible connections and non-sway modular steel building frames with bracings, are shown in Figure 2. This study focuses on the latter.

The structural behavior of modular steel buildings is totally different from that of traditional rigid or flexible frames. This indicates that the methods mentioned above are not applicable for modular steel buildings. As a new structural system, few research has been done on modular steel buildings. Annan[15,17,18] and Hong[16] studied the behavior of low-rise modular steel buildings under a series of ground motions. The concentrical bracing and double skinned steel plate were used to prevent lateral drift. It was found that the energy dissipation capacity of modular steel buildings was slightly better than that of regular frames. The former had various internal force distribution and force-transfer mechanisms compared with traditional frames. Lawson and Richards[1,3,19] carried out case studies on mid to relatively high-rise modular steel buildings in UK without considering the dynamic response under seismic loads. They presented some engineering projects in detail and experimentally investigated the robustness of a pair of modular units under unusual actions.

However, there is rare research and building codes on the effective length factors ( $K$-factors) of columns in modular steel buildings. In engineering practices, the flexible connection between modular units is always considered as pinned, and thus the French rules is used to determined $K$-factors[20]. This method is proven to be non-conservative as illustrated in this paper. Therefore, it is necessary to propose a new method to determine the $K$-factor of columns for modular steel buildings.

In this paper, the governing equations for determining the $K$-factor for non-sway modular steel buildings with bracings are derived. A simplified method, similar to the French rules, is proposed based on these governing equations and verified against analytical and numerical results. Finally, the influencing factors on $K$-factors are studied. 


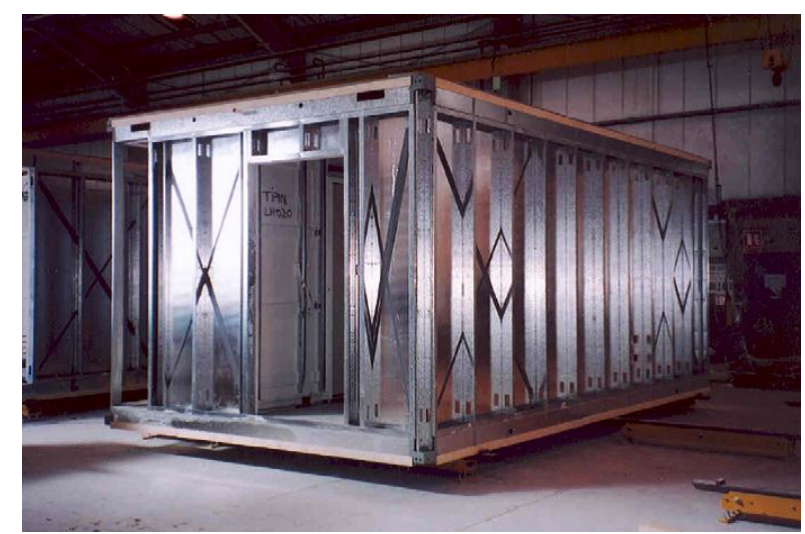

a. Continuously supported module (by Terrapin)

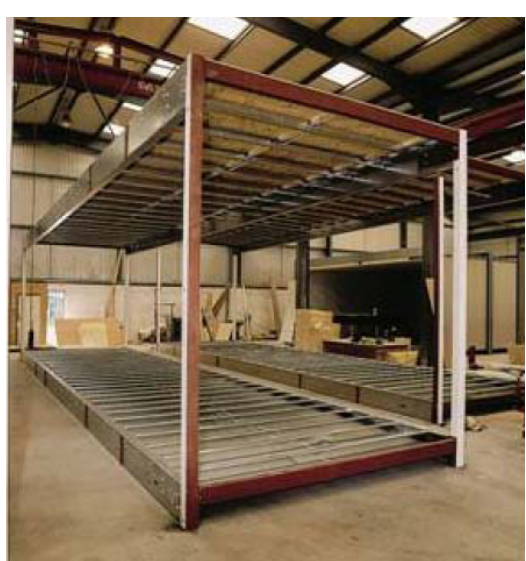

b. Corner-supported module (by Kingspan)

Figure 1. Typical Cases of Continuously supported Module and Corner-supported Module

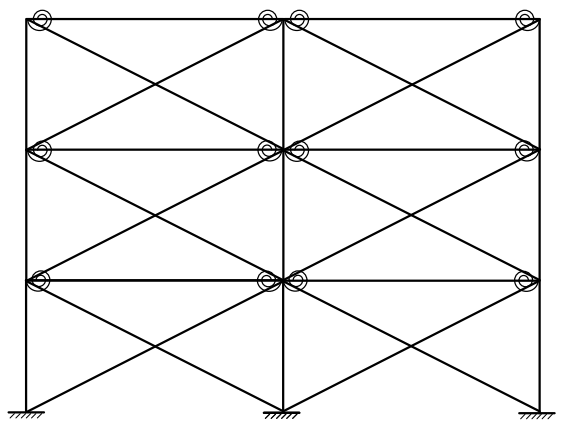

a. Braced Frame with Flexible Connections

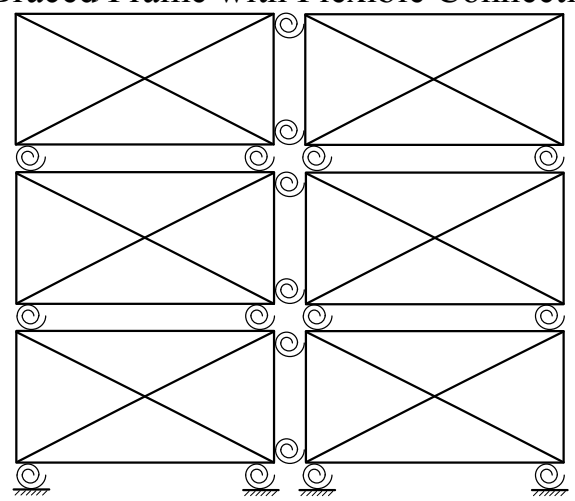

b. Non-sway Modular Steel Building Frame with Bracings

Figure 2. Models of Traditional and Modular Frames 


\section{MODELING ASSUMPTIONS}

Figure 3 shows the sub-assemblage model used for determining the $K$-factor of columns in a non-sway modular steel building. The model is composed of the column $\mathrm{c}_{2}$ (member CD in Figure 3 ), five restraining columns $\left(c_{1}, c_{3}, c_{4}, c_{5}\right.$, and $\left.c_{6}\right)$, and eight restraining beams $\left(b_{1}, b_{2}, b_{3}, b_{4}, b_{5}, b_{6}\right.$, $b_{7}$, and $b_{8}$ ). The semi-rigid connections between modular units are represented by a series of rotational springs.

For simplification, the following eight assumptions are adopted:

1. All members of the modular units behave elastically;

2. Axial forces in the beams are negligible;

3. All columns within a given storey buckle simultaneously;

4. Stability functions for all columns in the sub-assemblage model are identical;

5. At buckling of the sub-assemblage, the rotations at two ends of a beam are assumed to be of equal magnitude but opposite direction (i.e. beams are bent in a single curvature);

6. The beam-to-column connections within the modular unit are assumed to be rigid;

7. The connections between modular units are assumed to be semi-rigid;

8. At buckling of the sub-assemblage, the end rotations of columns in adjacent storey are proportional.

According to the assumptions 3 and 4, the deformations of columns $\mathrm{c}_{2}$ and $\mathrm{c}_{5}$ at buckling of the sub-assemblage are identical, and thus the sub-assemblage model shown in Figure 3 is bilaterally symmetrical which can be simplified. The simplified sub-assemblage model is shown in Figure 4, being composed of the column $\mathrm{c}_{2}$ (member $\mathrm{CD}$ in Figure 4$)$, two restraining columns $\left(\mathrm{c}_{1}\right.$ and $\left.\mathrm{c}_{3}\right)$, and four restraining beams $\left(b_{1}, b_{2}, b_{3}\right.$, and $\left.b_{4}\right)$.

In Chen's model of flexibly jointed and non-sway frames [12], the effect of non-linear connection stiffness was taken into account since the rotation between beams and columns was not negligible under a vertical load. For non-sway modular steel buildings, connections between beams and columns are assumed to be rigid, and the rotation between modular units in adjacent storey is negligible as the designed vertical load of each storey is identical. Therefore, the initial rotational stiffness of the semi-rigid connections can be used for modular steel buildings in unloading and loading conditions. 


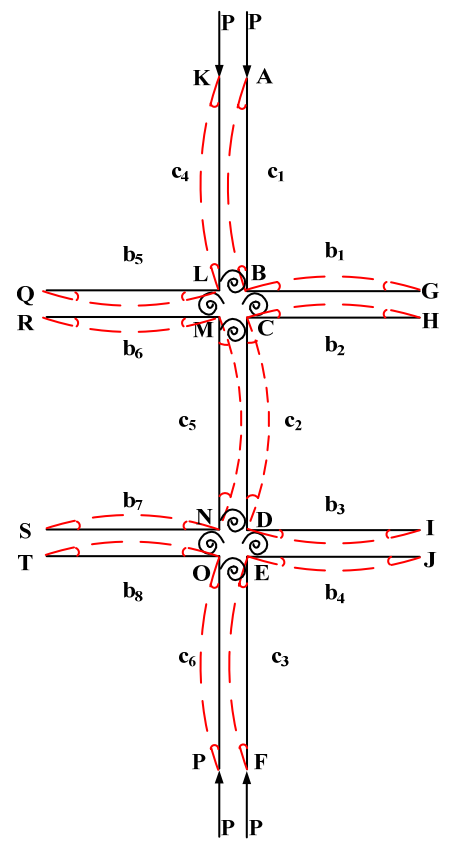

Figure 3. Sub-assemblage Model without Lateral Sway

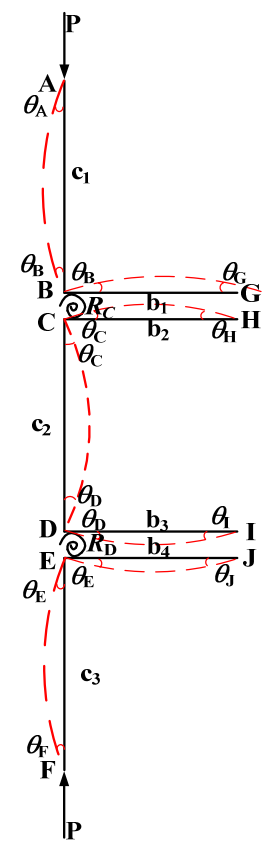

Figure 4. Simplified Sub-assemblage Model without Lateral Sway

\section{SLOPE DEFLECTION EQUATIONS OF MEMBERS}

Since the beam-to-column connections in a single modular unit are assumed rigid, the slope deflection equations of beam and column members in a non-sway modular unit are identical to those of traditional non-sway frames.

The beam element $\mathrm{AB}$ with end moments $M_{A B}$ and $M_{B A}$ is shown in Figure 5. For the sub-assemblage model with the assumed deflected shape $\theta_{A}=-\theta_{B}$, as shown in Figure 5 , the slope-deflection equations are generally expressed in terms of $\theta_{A}$ as: 
$M_{A B}=2 \frac{E I_{b}}{L_{b}} \theta_{A}$

where $L_{b}$ is beam length; $E I_{b}$ is flexural rigidity of beam; $\theta_{A}$ and $\theta_{B}$ are corresponding nodal rotations.

Figure 6 shows the model of the column element $\mathrm{CD}$ subjected to an axial force $P$ and end moments $M_{C D}$ and $M_{D C}$. The slope-deflection equations of the column CD are represented by stability functions as [12]:

$$
\begin{aligned}
& M_{C D}=\frac{E I_{c}}{L_{c}}\left[s_{i i} \theta_{C}+s_{i j} \theta_{D}\right] \\
& M_{D C}=\frac{E I_{c}}{L_{c}}\left[s_{j i} \theta_{C}+s_{j j} \theta_{D}\right]
\end{aligned}
$$

where $L_{c}$ and $E I_{c}$ are the length and flexural rigidity of the column, respectively; $\quad s k l(k, l=i$ or $j)$ are the stability functions defined as:

$$
\begin{gathered}
s_{i i}=s_{j j}=\frac{k L_{c} \sin k L_{c}-\left(k L_{c}\right)^{2} \cos k L_{c}}{2-2 \cos k L_{c}-k L_{c} \sin k L_{c}} \\
s_{i j}=s_{j i}=\frac{\left(k L_{c}\right)^{2}-k L_{c} \sin k L_{c}}{2-2 \cos k L_{c}-k L_{c} \sin k L_{c}}
\end{gathered}
$$

where

$k=\sqrt{\frac{P}{E I}}$

The $K$-factor of a column can therefore be obtained by Equation (6) as:

$$
K=\frac{\pi}{k L_{c}}
$$

Substituting Eq. (7) into Eqs. (4) and (5), the stability functions $s k l(k, l=i$ or $j)$ can be expressed by $K$ as:

$$
\begin{aligned}
& s_{i i}=s_{j j}=\frac{\frac{\pi}{K} \sin \frac{\pi}{K}-\left(\frac{\pi}{K}\right)^{2} \cos \frac{\pi}{K}}{2-2 \cos \frac{\pi}{K}-\frac{\pi}{K} \sin \frac{\pi}{K}} \\
& s_{i j}=s_{j i}=\frac{\left(\frac{\pi}{K}\right)^{2}-\frac{\pi}{K} \sin \frac{\pi}{K}}{2-2 \cos \frac{\pi}{K}-\frac{\pi}{K} \sin \frac{\pi}{K}}
\end{aligned}
$$

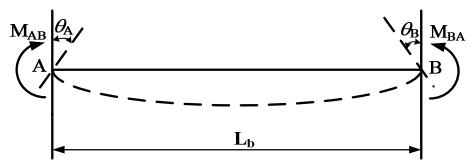

Figure 5. Model of Non-sway Beam Element subjected to End Moments 


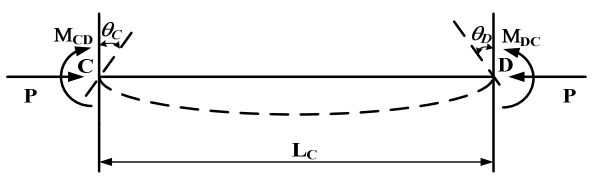

Figure 6. Model of Non-sway Column Element subjected to End Moments

\section{Governing Equations for $K$-factor}

According to the assumption 4, the rotations of beams in the simplified sub-assemblage (Figure 4) can be simplified as: $\theta_{C}=-\theta_{H}, \theta_{D}=-\theta_{I}, \theta_{B}=-\theta_{G}$ and $\theta_{E}=-\theta_{D}$. The nodal rotations of joint $\mathrm{B}$ and E can be expressed as:

$\theta_{B}=\theta_{C}-\frac{M_{C}}{R_{C}}$
$\theta_{E}=\theta_{D}-\frac{M_{D}}{R_{D}}$

where $R_{C}$ and $R_{D}$ are the stiffness of the semi-rigid connections, respectively; $M_{C}$ and $M_{D}$ are the moments of the semi-rigid connections, respectively.

According to the assumption 8 , the nodal rotations of joint $\mathrm{A}$ and $\mathrm{F}$ can be expressed as:

$$
\begin{aligned}
& \theta_{A}=\left(\theta_{C}-\frac{M_{C}}{R_{C}}\right) \times \frac{\theta_{D}}{\theta_{C}} \\
& \theta_{F}=\left(\theta_{D}-\frac{M_{D}}{R_{D}}\right) \times \frac{\theta_{C}}{\theta_{D}}
\end{aligned}
$$

The end moments of beam and column elements shown in Figure4 can thus be expressed as:

$$
\begin{aligned}
& M_{B G}=2 i_{b 1}\left(\theta_{C}-\frac{M_{B}}{R_{C}}\right) \\
& M_{C H}=2 i_{b 2} \theta_{C} \\
& M_{D I}=2 i_{b 3} \theta_{D} \\
& M_{E J}=2 i_{b 4}\left(\theta_{D}-\frac{M_{E}}{R_{D}}\right) \\
& M_{B A}=i_{c 1}\left[s_{i i}\left(\theta_{C}-\frac{M_{B}}{R_{C}}\right)+s_{i j}\left(\theta_{D}-\frac{M_{B}}{R_{C}} \frac{\theta_{D}}{\theta_{C}}\right)\right] \\
& M_{C D}=i_{c 2}\left(s_{i i} \theta_{C}+s_{i j} \theta_{D}\right) \\
& M_{D C}=i_{c 2}\left(s_{i i} \theta_{D}+s_{i j} \theta_{C}\right) \\
& M_{E F}=i_{c 3}\left[s_{i i}\left(\theta_{D}-\frac{M_{E}}{R_{D}}\right)+s_{i j}\left(\theta_{C}-\frac{M_{E}}{R_{D}} \frac{\theta_{C}}{\theta_{D}}\right)\right]
\end{aligned}
$$

where $M_{B G}$ is the end moment of beam BG at joint $B ; M_{C H}$ is the end moment of beam $\mathrm{CH}$ at joint $C ; M_{D I}$ is the end moment of beam DI at joint $D ; M_{E J}$ is the end moment of beam EJ at joint $E$; $M_{B A}$ is the end moment of column BA at joint $B ; M_{C D}$ and $M_{D C}$ are the end moments of column $C D$ at joints $C$ and $D$, respectively; $M_{E F}$ is the end moment of column $E F$ at joint $E$; $i_{b m}(m=1,2,3$, or 4$)$ are the linear stiffness of the beams, and $i_{c n}(n=1,2$ or 3$)$ are the linear stiffness of the columns: 


$$
\begin{aligned}
& i_{b m}=\frac{E I_{b m}}{L_{b}} \\
& i_{c m}=\frac{E I_{c m}}{L_{c}}
\end{aligned}
$$

The moment equilibriums at points $B, C, D$, and $E$ can be expressed as:

$$
\begin{aligned}
& -M_{C}+M_{B A}+M_{B G}=0 \\
& M_{C}+M_{C H}+M_{C D}=0 \\
& -M_{D}+M_{E F}+M_{E J}=0 \\
& M_{D}+M_{D I}+M_{D C}=0
\end{aligned}
$$

By solving Equations (14) (27), the equations for $\theta_{C}, \theta_{D}$, and $K$ can be obtained as:

$$
\begin{aligned}
& \left(s_{i i} R_{C} i_{c 1}+2 R_{C} i_{b 1}+2 R_{C} i_{b 2}+2 s_{i i} i_{c 1} i_{b 2}+4 i_{b 1} i_{b 2}+s_{i i} R_{C} i_{c 2}+s_{i i}{ }^{2} i_{c 1} i_{c 2}+2 s_{i i} i_{b 1} i_{c 2}\right) \theta_{C}{ }^{2} \\
& +\left(s_{i j} R_{C} i_{c 1}+2 s_{i j} i_{b 2} i_{c 1}+2 s_{i i} s_{i j} i_{c 1} i_{c 2}+s_{i j} R_{C} i_{c 2}+2 s_{i j} i_{b 1} i_{c 2}\right) \theta_{C} \theta_{D}+s_{i j}{ }^{2} i_{c 1} i_{c 2} \theta_{D}{ }^{2}=0 \\
& \left(s_{i i} R_{D} i_{c 3}+2 R_{D} i_{b 4}+2 R_{D} i_{b 3}+2 s_{i i} i_{b 3} i_{c 3}+4 i_{b 3} i_{b 4}+s_{i i} R_{D} i_{c 2}+s_{i i}{ }^{2} i_{c 2} i_{c 3}+2 s_{i i} i_{b 4} i_{c 2}\right) \theta_{D}{ }^{2} \\
& +\left(s_{i j} R_{D} i_{c 3}+2 s_{i j} i_{c 3} i_{b 3}+2 s_{i i} s_{i j} i_{c 2} i_{c 3}+s_{i j} R_{D} i_{c 2}+2 s_{i j} i_{b 4} i_{c 2}\right) \theta_{C} \theta_{D}+s_{i j}{ }^{2} i_{c 2} i_{c 3} \theta_{C}{ }^{2}=0
\end{aligned}
$$

The relative beam-to-column stiffness factor $G$ and relative unit connection to column stiffness factor $\mathrm{J}$ can be defined as:

$$
\begin{array}{llll}
G_{B}=\frac{i_{b 1}}{i_{c 1}} & G_{C}=\frac{i_{b 2}}{i_{c 2}} & G_{D}=\frac{i_{b 3}}{i_{c 2}} & G_{E}=\frac{i_{b 4}}{i_{c 3}} \\
J_{B}=\frac{R_{C}}{i_{c 1}} & J_{C}=\frac{R_{C}}{i_{c 2}} & J_{D}=\frac{R_{D}}{i_{c 2}} & J_{E}=\frac{R_{D}}{i_{c 3}}
\end{array}
$$

By using Eqs. (30) and (31), Eqs. (28) and (29) can be simplified as:

$$
\begin{aligned}
& \left(s_{i i} J_{C}+2 J_{C} G_{B}+2 J_{C} G_{C}+2 s_{i i} G_{C}+4 G_{B} G_{C}+s_{i i} J_{B}+s_{i i}{ }^{2}+2 s_{i i} G_{B}\right) \theta_{C}{ }^{2} \\
& +\left(s_{i j} J_{C}+2 s_{i j} G_{C}+2 s_{i i} s_{i j}+s_{i j} J_{B}+2 s_{i j} G_{B}\right) \theta_{C} \theta_{D}+s_{i j}{ }^{2} \theta_{D}{ }^{2}=0 \\
& \left(s_{i i} J_{D}+2 J_{D} G_{E}+2 J_{E} G_{D}+2 s_{i i} G_{D}+4 G_{D} G_{E}+s_{i i} J_{E}+s_{i i}{ }^{2}+2 s_{i i} G_{E}\right) \theta_{D}{ }^{2} \\
& +\left(s_{i j} J_{D}+2 s_{i j} G_{D}+2 s_{i i} s_{i j}+s_{i j} J_{E}+2 s_{i j} G_{E}\right) \theta_{C} \theta_{D}+s_{i j}{ }^{2} \theta_{C}{ }^{2}=0
\end{aligned}
$$

The Eqs. 32 and 33 are in a binary quadric form about $\theta_{C}$ and $\theta_{D}$, which can be also expressed as:

$$
\left(\theta_{C}+\alpha_{1} \theta_{D}\right)\left(\alpha_{2} \theta_{C}+\alpha_{3} \theta_{D}\right)=0
$$

$$
\left(\alpha_{4} \theta_{C}+\theta_{D}\right)\left(\alpha_{5} \theta_{C}+\alpha_{6} \theta_{D}\right)=0
$$

where the coefficients $\alpha_{1}, \alpha_{2}, \alpha_{3}, \alpha_{4}, \alpha_{5}$, and $\alpha_{6}$ can be determined by:

$$
\begin{aligned}
& \alpha_{2}=s_{i i} J_{C}+2 J_{C} G_{B}+2 J_{B} G_{C}+2 s_{i i} G_{C}+4 G_{B} G_{C}+s_{i i} J_{B}+s_{i i}{ }^{2}+2 s_{i i} G_{B} \\
& \alpha_{1} \alpha_{3}=s_{i j}{ }^{2}
\end{aligned}
$$




$$
\begin{aligned}
& \alpha_{1} \alpha_{2}+\alpha_{3}=s_{i j} J_{C}+2 s_{i j} G_{C}+2 s_{i i} s_{i j}+s_{i j} J_{B}+2 s_{i j} G_{B} \\
& \alpha_{6}=s_{i i} J_{D}+2 J_{D} G_{E}+2 J_{E} G_{D}+2 s_{i i} G_{D}+4 G_{D} G_{E}+s_{i i} J_{E}+s_{i i}{ }^{2}+2 s_{i i} G_{E} \\
& \alpha_{4} \alpha_{5}=s_{i j}{ }^{2} \\
& \alpha_{4} \alpha_{6}+\alpha_{5}=s_{i j} J_{D}+2 s_{i j} G_{D}+2 s_{i i} s_{i j}+s_{i j} J_{E}+2 s_{i j} G_{E}
\end{aligned}
$$

The general governing equations for the $K$-factor of column $\mathrm{c}_{2}$ can therefore be derived from Eqs. 34 and 35 as:

$\operatorname{det}\left|\begin{array}{ll}\alpha_{2} & \alpha_{3} \\ \alpha_{5} & \alpha_{6}\end{array}\right|=0$

By solving (36) (42), the solution of $K$-factor of column $\mathrm{c}_{2}$ is derived as:

$$
\begin{aligned}
& \left(s_{i i}^{2}+2\left(J_{C} G_{B}+\left(J_{B}+2 G_{B}\right) G_{C}\right)+s_{i i}\left(J_{B}+J_{C}+2\left(G_{B}+G_{C}\right)\right)\right)\left(s_{i i}^{2}+2\left(J_{E} G_{D}\right.\right. \\
& \left.\left.+\left(J_{D}+2 G_{D}\right) G_{E}\right)+s_{i i}\left(J_{D}+J_{E}+2\left(G_{D}+G_{E}\right)\right)\right)-\frac{1}{4} s_{i j}^{2}\left(2 s_{i i}+J_{B}+J_{C}+\right. \\
& \left.2\left(G_{B}+G_{C}\right)+\sqrt{J_{B}^{2}+2 J_{B}\left(J_{C}+2 G_{B}-2 G_{C}\right)+\left(J_{C}-2 G_{B}+2 G_{C}\right)^{2}}\right)\left(2 s_{i i}+\right. \\
& \left.J_{D}+J_{E}+2\left(G_{D}+G_{E}\right)+\sqrt{J_{D}^{2}+2 J_{D}\left(J_{E}+2 G_{D}-2 G_{E}\right)+\left(J_{E}-2 G_{D}+2 G_{E}\right)^{2}}\right)=0
\end{aligned}
$$

\section{SIMPLIFIED SOLUTION FOR K-FACTOR}

The Eq. 43 can be solved by numerical methods to obtain the $K$-factor. However the numerical solution is too complicated to be used in practice. Therefore, a simple fitting formula for $K$-factor based on the numerical solutions of Eq. 43 was obtained in this section.

For non-sway steel frames, the French design rules for steel structures [21], also called "French rules", have been widely used in Europe and China since 1966 with the following approximate solution:

$$
K=\frac{0.64 G_{A}^{\prime} G_{B}^{\prime}+1.4\left(G_{A}^{\prime}+G_{B}^{\prime}\right)+3}{1.28 G_{A}^{\prime} G_{B}^{\prime}+2\left(G_{A}^{\prime}+G_{B}^{\prime}\right)+3}
$$

where the restraint factors $G_{i}{ }^{\prime}(i=A, B)$ is the relative stiffness of all the columns connected at the joint $i$ of a steel frame to that of all the beams connected at joint $i$, i.e.,

$G_{i}^{\prime}=\frac{\sum\left(I_{c} / L_{c}\right)}{\sum\left(I_{b} / L_{b}\right)}$

Qualitative analyses showed that when the rotation stiffness $R_{C}$ and $R_{D}$ of the connections between the modular units are large enough, a non-sway modular steel building can be treated as a traditional non-sway frame, and thus the simple formula of the French rule is applicable. This means the format of Eq. (44) can be used for modular steel buildings. Therefore, the simple formula for $K$-factor of modular steel buildings can be assumed as:

$$
K=\frac{0.64 G_{C}{ }^{\prime \prime} G_{D}{ }^{\prime}+1.4\left(G_{C}{ }^{\prime}+G_{D}{ }^{\prime \prime}\right)+3}{1.28 G_{C} G_{D}{ }^{\prime \prime}+2\left(G_{C}{ }^{\prime \prime}+G_{D}{ }^{\prime \prime}\right)+3}
$$


where

$$
\begin{aligned}
& G_{C}{ }^{\prime \prime}=\frac{J_{C} G_{B}+\left(J_{B}+\alpha\right) G_{C}}{J_{C}+J_{B}+\alpha} \\
& G_{D}{ }^{\prime \prime}=\frac{J_{D} G_{E}+\left(J_{E}+\alpha\right) G_{D}}{J_{D}+J_{E}+\alpha}
\end{aligned}
$$

where $G_{\mathrm{C}}$ "and $G_{\mathrm{D}}$ "are the modified relative stiffness factors of column $\mathrm{CD}$ at node $\mathrm{C}$ and $\mathrm{D}$, and $\alpha$ is a constant to be determined. When $R_{C}$ and $R_{D}$ are large enough, Eqs. (46) (48) can be reduced to Eqs. 44 and 45.

To determine $\alpha$, the $K$-factors corresponding to various restraint factors, $G_{B}, G_{C}, G_{D}, G_{E}, J_{B}, J_{C}, J_{D}$, $J_{E}$, obtained from numerical solutions of Eq. (43) were employed. Using the least-squared method to fit the simple formula, the value of $\alpha$ was determined as 0.2 . To evaluate the effectiveness of the simple formula Eq. (46), $K$-factors were obtained from Eq. (43) and Eq. (46) for practical values of restraint factors $\left(G_{B}, G_{C}, G_{D}, G_{E}, J_{B}, J_{C}, J_{D}, J_{E}\right)$ ) and the results are listed in Table 1 . The $K_{\mathrm{e}}$ and $K_{\mathrm{a}}$ denote the $K$-factors obtained from Eq. (43) and Eq. (46), respectively. The error between them (Error 1 ) is defined as:

$$
\text { Error }_{1}=\frac{K_{a}-K_{e}}{K_{e}} \times 100 \%
$$

The positive and negative Error 1 indicate the underestimation and overestimation of $K$-factors from the simple formula Eq. (46). From Table 1, it can be seen that, in most cases, the simple formula overestimated the $K$-factors with the maximum error within $6 \%$. The average Error 1 was $-1.11 \%$ and the average absolute Error 1 was $1.35 \%$, which showed that the simple formula can reasonably predict the $K$-factor of columns of modular steel buildings.

\section{DEMONSTRATION OF A TYPICAL MODULAR STEEL BUILDING}

A six-storey modular steel building consisting of 10 modules was used to further demonstrate the effectiveness of the simple formula for $K$-factor of modular steel buildings as shown in Figure 7. The dimension of each module was $3.0 \mathrm{~m}$ (height) $\times 6.0 \mathrm{~m}$ (length) $\times 2.4 \mathrm{~m}$ (width). Considering the accuracy and efficiency, the finite element software SAP2000 was used to model the buckling behavior of this modular steel building. The beam and column elements of each module were meshed automatically with a maximum length of $0.1 \mathrm{~m}$. The flexible connections were modeled using linear springs of which three translational degrees of freedoms (DoFs) were constrained. The rotation stiffness of the connections with respect to the $x$ - and $y$-axis was set as $4,930 \mathrm{kN} \cdot \mathrm{m} / \mathrm{rad}$, which was the initial connection stiffness of the joint obtained by previous experimentation [20]. In order to restrict the buckling in the second to fifth storey, three translational DoFs and two rotational DoFs in the $\mathrm{O}-x y$ plane of the nodes in the first storey, and both the translational DoFs and rotational DoFs in the $\mathrm{O}-x y$ plane of the nodes in the sixth storey, were constrained. The two translational DoFs in the $\mathrm{O}-x y$ plane of the end nodes for other columns were constrained to simulate the non-sway situation. The critical load of first buckling mode, $\mathrm{P}$, was obtained through eigenvalue buckling analyses and the $K$-factor was determined by using Eqs. 6 and 7 .

Figure 8 shows the first buckling mode shape of this modular steel building which fits the assumptions well. It can be concluded that the assumptions are reasonable for accurately predicting the buckling behavior of modular steel buildings. The $K$-factors $K_{\mathrm{n}}$ obtained from the numerical simulation in SAP2000 are listed in Table 1. The error between $K_{\mathrm{n}}$ and $K_{\mathrm{a}}\left(\right.$ Error $\left._{2}\right)$ is defined as: 
Error $_{2}=\frac{K_{n}-K_{a}}{K_{a}} \times 100 \%$

The average Error 2 was $-2.66 \%$ and the average of the absolute value of Error 1 was $4.82 \%$, which indicates accepted accuracy of the simple formula. Most of the $K$-factors obtained by the numerical model were smaller than those determined by the simple formula. This was because, in the sub-assemblage model, similar deformation curves of columns in adjacent storey were assumed, while in the numerical model the deformation of columns was restrained by boundary conditions. The restraints in the numerical model were stronger than those in the sub-assemblage model.

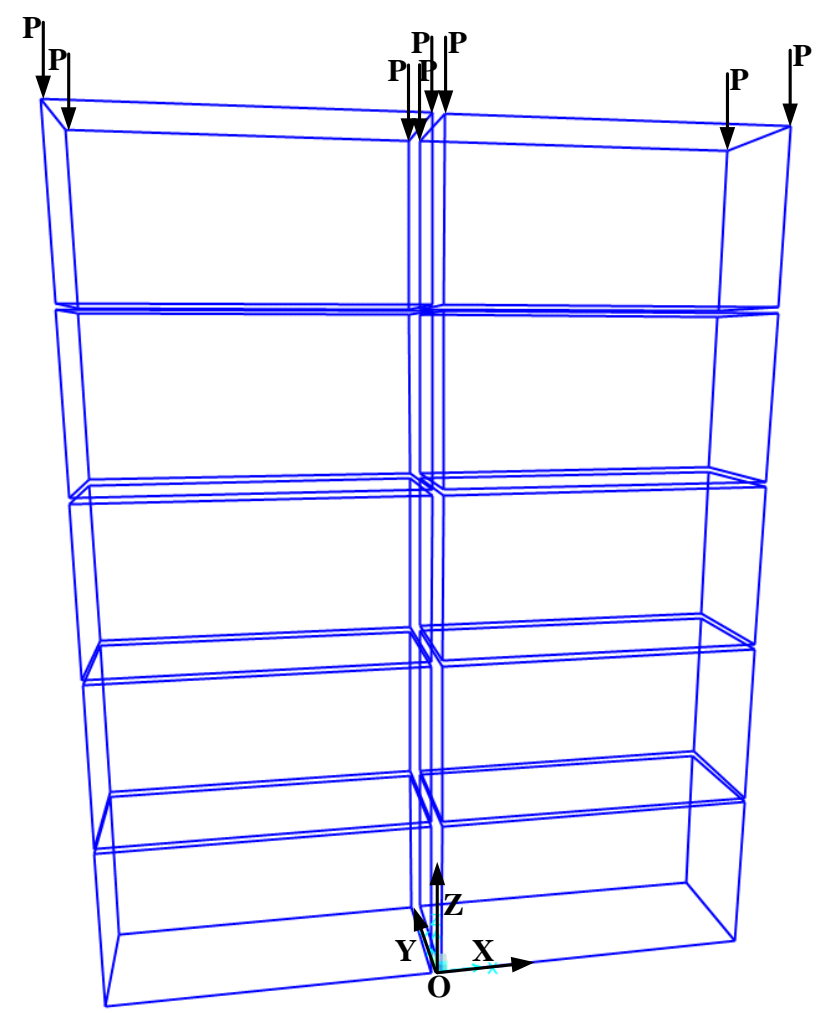

Figure 7. Numerical Model of a Typical Modular Steel Building

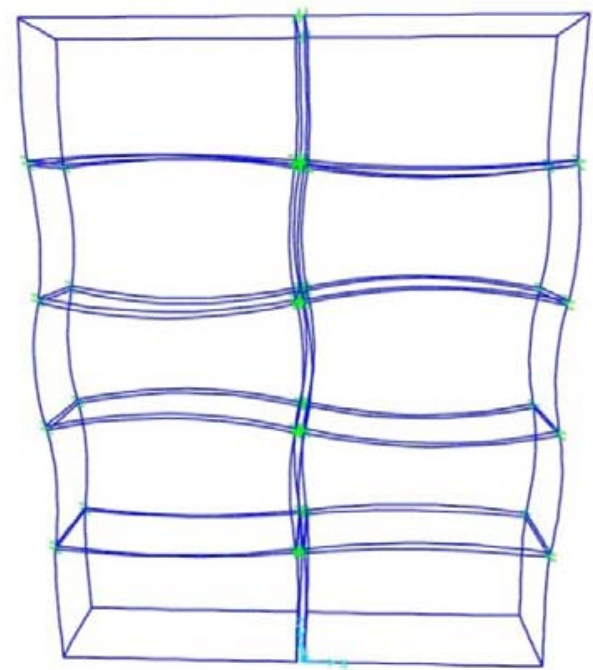

Figure 8. First Buckling Shape of the Modular Steel Building in the Numerical Model 
Table 1. Comparison of $K$-factors obtained by Governing Equation, Simple Formula, and Numerical Model

\begin{tabular}{llllllllllllll}
\hline \multicolumn{1}{l}{ Restraint factors } & & & & & & & & & & & & & \\
$G_{B}$ & $G_{C}$ & $G_{D}$ & $G_{E}$ & $J_{B}$ & $J_{C}$ & $J_{D}$ & $J_{E}$ & & $K_{\mathrm{a}}$ & $\begin{array}{l}\text { Error }_{1} \\
(\%)\end{array}$ & $K_{\mathrm{n}}$ & $\begin{array}{l}\text { Error }_{2} \\
(\%)\end{array}$ \\
& & & & & & & & & & & & \\
\hline 0.2 & 0.6 & 0.6 & 0.6 & 0.75 & 0.75 & 0.75 & 0.75 & 0.8618 & 0.8554 & -0.74 & 0.8198 & -4.13 \\
0.2 & 1.5 & 1.5 & 1.5 & 3.00 & 3.00 & 3.00 & 3.00 & 0.7670 & 0.7601 & -0.90 & 0.7159 & -5.75 \\
0.4 & 0.6 & 0.8 & 0.2 & 0.50 & 4.00 & 5.00 & 2.00 & 0.8806 & 0.8773 & -0.37 & 0.8421 & -4.00 \\
0.4 & 1.5 & 1.0 & 2.5 & 4.00 & 0.50 & 0.25 & 1.00 & 0.7519 & 0.7432 & -1.15 & 0.7187 & -3.27 \\
0.6 & 0.4 & 0.8 & 1.0 & 4.00 & 0.25 & 0.75 & 3.00 & 0.8342 & 0.8367 & 0.30 & 0.7997 & -4.44 \\
0.6 & 1.5 & 2.5 & 0.2 & 0.75 & 2.00 & 4.00 & 0.50 & 0.8495 & 0.8198 & -3.50 & 0.8583 & 4.54 \\
0.8 & 0.2 & 0.8 & 2.5 & 2.00 & 3.00 & 4.00 & 0.75 & 0.7636 & 0.7599 & -0.49 & 0.7192 & -5.33 \\
0.8 & 1.0 & 2.5 & 0.8 & 0.25 & 0.50 & 0.75 & 4.00 & 0.7392 & 0.7326 & -0.89 & 0.6932 & -5.33 \\
1.0 & 0.4 & 1.5 & 0.2 & 2.00 & 5.00 & 1.00 & 4.00 & 0.7816 & 0.7757 & -0.76 & 0.7339 & -5.34 \\
1.0 & 1.5 & 0.4 & 1.0 & 0.25 & 1.00 & 5.00 & 0.75 & 0.7768 & 0.7748 & -0.26 & 0.7348 & -5.15 \\
1.5 & 0.8 & 2.0 & 0.2 & 3.00 & 0.50 & 2.00 & 0.75 & 0.8294 & 0.7996 & -3.59 & 0.8317 & 3.87 \\
1.5 & 2.0 & 0.8 & 1.5 & 0.25 & 2.00 & 0.50 & 5.00 & 0.7555 & 0.7568 & 0.17 & 0.7378 & -2.52 \\
2.0 & 0.8 & 1.5 & 2.5 & 0.50 & 2.00 & 0.75 & 0.25 & 0.7111 & 0.6988 & -1.73 & 0.6766 & -3.11 \\
2.0 & 2.5 & 0.4 & 0.8 & 3.00 & 0.25 & 4.00 & 2.00 & 0.7386 & 0.7428 & 0.57 & 0.6812 & -8.35 \\
2.5 & 0.4 & 2.0 & 2.5 & 0.25 & 0.75 & 3.00 & 2.00 & 0.7364 & 0.6936 & -5.82 & 0.7357 & 5.73 \\
2.5 & 1.5 & 0.6 & 0.8 & 2.00 & 4.00 & 0.5 & 0.25 & 0.7452 & 0.7482 & 0.40 & 0.7015 & -6.26 \\
\hline
\end{tabular}

\section{INFLUENCING FACTORS OF K-FACTORS}

All the restraint factors $\left(G_{B}, G_{C}, G_{D}, G_{E}, J_{B}, J_{C}, J_{D}, J_{E}\right.$, ) may affect the $K$-factors. Furthermore, from qualitative analyses, it was found that the ratios of the relative beam-to-column stiffness $G_{B} / G_{C}$ and $G_{D} / G_{E}$ also had significant effects on the $K$-factors. Considering the symmetry of the sub-assemblage model, the effects of $G_{B} / G_{C}$ and $G_{D} / G_{E}$ on the $K$-factor should be the same. To study the effects of $G_{B} / G_{C}$ on the $K$-factor of columns, set $J_{B}=J_{C}=J_{D}=J_{E}$ and $G_{B}=G_{D}=G_{E}=1$. Using the governing equation, eighty $K$-factors with respect to different values of $G_{C}$ and $J_{C}$ were obtained and presented in Figure 9. According to these results, several conclusions can be drawn as follows:

(1) When $G_{B} / G_{C}=1$, the $K$-factor was independent of $J_{C}$.

(2) The trend of $K$-factors with respect to $J_{C}$ changed with $G_{B} / G_{C}$. When $G_{B} / G_{C}>1$, the $K$-factor decreased with the increasing $J_{C}$, and tended to converge. This was because the relative beam-to-column stiffness of column $\mathrm{c}_{1}$ at node $\mathrm{C}$ was larger than that of column $\mathrm{c}_{2}$. Therefore, at buckling, the moment in the flexible joint was opposite to the rotation of column $\mathrm{c}_{2}$ at node $\mathrm{C}$, which enhanced the restraint of column $\mathrm{c}_{2}$ and reduced its $K$-factor. The moment increased with the increment of $J_{C}$ and tended to converge. On the contrary, when $G_{B} / G_{C}<1$, the $K$-factor increased as $J_{C}$ increased, and attempted to converge.

(3) The $K$-factor may increase with the increasing $J_{C}$. This indicates that the assumption of pinned connections between modular units in Mao's research [20] and some engineering practices may overestimate the stability of columns for modular steel buildings, up to $15 \%$. Hence, the method of pinned connections should not be adopted for the design of modular steel buildings.

(4) The influence of $J_{C}$ on the $K$-factor depended on $G_{B} / G_{C}$. The more the $G_{B}$ differed from $G_{C}$, the greater influence $J_{C}$ will have on the $K$-factor. It indicates that the moment in the flexible joint to 
connect modular units will be significantly influenced by $G_{B} / G_{C}$. The more the $G_{B}$ differed from $G_{C}$, the larger the moment. The rotation of the flexible joint can be obtained by Eqs. (28) and (29). It was found that when $G_{B} / G_{C}$ was 0.35 or 2.64 , the rotation of the flexible joint could reach $0.5^{\circ}$, which was half of the elastic limit angle [20]. Thus, it is suggested that, in the design of modular steel buildings for $G_{B} / G_{C}$ or $G_{D} / G_{E}$ beyond the range of $0.38 \sim 2.64$, the joint must be double-checked and strengthened. The range given above was established on several preliminary conditions and its applicability needs to be further studied.

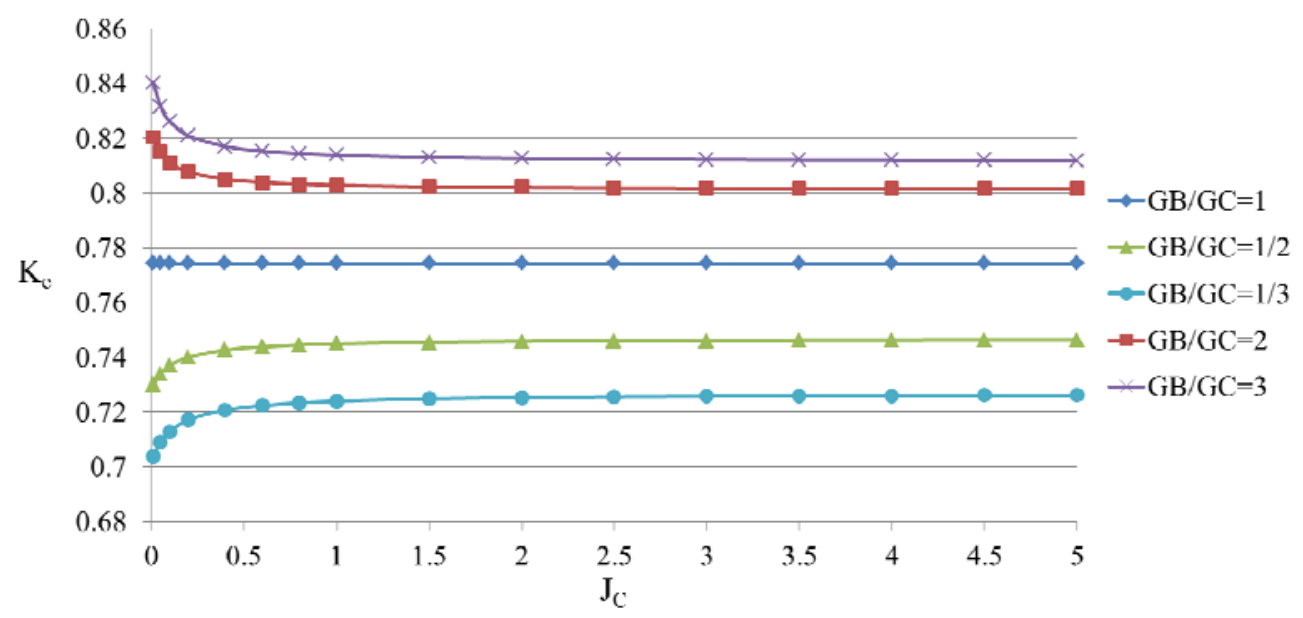

Figure 9. Variation of $K_{e}-J_{C}$ Curves against Different $G_{B} / G_{C}$

\section{CONCLUSIONS}

This paper proposed analytical solutions of $K$-factors of columns in non-sway modular steel buildings with bracings. The accuracy of the proposed method was verified against numerical results. The following conclusions can be drawn:

(1) The governing equations for determining the $K$-factor of columns for non-sway modular steel buildings were derived based on a sub-assemblage model. Several assumptions applicable to non-sway frames with flexible connections were proposed. It was found that it was not suitable to directly apply the available methods such as the alignment chart and French rule to determine $K$-factors for modular steel buildings.

(2) The simple formula for determining the $K$-factor for non-sway modular steel buildings was obtained using least-squared method to fit the proposed governing equations. The accuracy of the proposed simple formula was verified against governing equations given the maximum errors within $6 \%$ and the average absolute error of $1.35 \%$.

(3) The effectiveness of the simple formula was also verified against numerical simulation of a six-storey frame with 10 modules. The maximum error between the analytical and numerical results of $K$-factors was within $8.35 \%$. It indicated the good applicability of the proposed simplified method to practical cases.

(4) The variation of $K$-factors with $J_{C}$ depended on $G_{B} / G_{C}$. The assumption of pinned connections between modular units was found to be non-conservative. Furthermore, it is recommended to check and strengthen the flexible connections in the modular steel buildings with too small or too large $G_{B} / G_{C}$. 


\begin{tabular}{|c|c|}
\hline NOTATION & \\
\hline$E I b$ & Flexural rigidity of beam \\
\hline EIc & Flexural rigidity of column \\
\hline$L b$ & Length of beam \\
\hline Lc & Length of column \\
\hline$M A B, M B A$ & End moment at joints $A$ and $B$ \\
\hline $\begin{array}{l}M_{B G}, M_{C H}, M_{D I} \\
M_{E J}\end{array}$ & End moment of beam at joints $B, C, D$, and $E$ \\
\hline$M_{C D}, M_{D C}, M_{E F}$ & End moment of column at joints $C, D$, and $E$ \\
\hline$M_{C}, M_{D}$ & Moments of the semi-rigid connections at joints $\mathrm{C}$ and $\mathrm{D}$ \\
\hline$\theta_{A}, \theta_{B}, \theta_{C}, \theta_{D}, \theta_{E}, \theta_{F}$ & Nodal rotations at joints $A, B, C, D, E$, and $F$ \\
\hline$S_{k l}$ & Stability functions $\left(\left(\theta_{A}, \theta_{B}, \theta_{C}, \theta_{D}, \theta_{E}, \theta_{F}\right)\right.$ \\
\hline$k$ & $\sqrt{ } P / E I_{c}$ \\
\hline$K$ & Effective length factor of column \\
\hline$P$ & Axial force subjected to column \\
\hline$R_{C}, R_{D}$ & Connection stiffness of the semi-rigid connections at joints $\mathrm{C}$ and $\mathrm{D}$ \\
\hline$i_{b m}$ & Linear stiffness of the beams $(m=1,2,3$, or 4$)$ \\
\hline$i_{c n}$ & linear stiffness of the columns $(n=1,2$, or 3$)$ \\
\hline$G_{B}, G_{C}, G_{D}, G_{E}$ & Relative beam-to-column stiffness factors at joints B, C, D, and E \\
\hline$J_{B}, J_{C}, J_{D}, J_{E}$ & Relative joint to column stiffness factors at joints $B, C, D$, and $E$ \\
\hline$G_{A^{\prime}}, G_{B}{ }^{\prime}$ & $\begin{array}{l}\text { Relative stiffness of all the columns connected at joints } A \text { and } B \text { to that of all } \\
\text { the beams }(\mathrm{i}=\mathrm{A}, \mathrm{B})\end{array}$ \\
\hline$G_{\mathrm{C}}^{\prime \prime}, G_{\mathrm{D}}^{\prime \prime}$ & Modified relative stiffness factors of column CD at joints C and D \\
\hline
\end{tabular}

\section{REFERENCES:}

[1] Lawson, R.M., Richards, J., "Modular Design for High-rise Buildings", Proceedings of the ICE - Structures and Buildings, 2010, Vol. 163, pp. 151-64.

[2] Fathieh, A., "Nonlinear Dynamic Analysis of Modular Steel Buildings in Two and Three Dimensions", [Master of Applied Science], Toronto: University of Toronto, 2013.

[3] Lawson, R.M., Ogden, R.G., "Hybrid' Light Steel Panel and Modular Systems", Thin-Walled Structures, 2008, Vol. 46, pp. 720-30.

[4] Construction AIOS.AISC 325-05 Steel Construction Manual, Thirteenth Edition, 2006.

[5] National Standard of Canada CAN/CSA-S16, 1-M89, Limit States Design of Steel Structures, 1989.

[6] European Convention for Constructional Steel Work ERFS, 1978.

[7] JGJ 99-98, Chinese Technical Specification for Steel Strucure of Tall Buildings.

[8] Dumonteil, P., "Simple Equations for Effective Length Factors", Engineering Journal, American Institute of Steel Construction, 1992, Third quarter: 111-5.

[9] AV, G., "A Collection of Experimental Moment-rotation Curves and Evaluation of Prediction Equations for Semi-rigid Connections", [Master], Nashville: Vanderbilt University, 1983.

[10] DA, N., "Steel Beam-to-column Connections: a Review of Test Data and Its Applicability to the Evaluation of Joint Behavior in Performance of Steel Frames", CIRIA Project Record 1985.

[11] Kishi, N.C.W., "Data Base of Steel Beam-to-column Connections", Structural Engineering Report. Structural Engineering Report, West Lafayette: Purdue University, 1986.

[12] Kishi, N., Chen, W.F., Goto, Y. and Komuro, M., "Effective Length Factor of Columns in Flexibly Jointed and Braced Frames", Journal of Constructional Steel Research, 1998, Vol. 47, pp. 93-118. 
[13] EM, L., "Effects of Connection Flexibility and Panel Zone Deformation on the Behavior of Plane Steel Frames", Ph.D., West Lafayette, Purdue University, 1985.

[14] RB. "Effect of End Restraint on Column Strength: Practical Applications", Engineering Journal, AISC, 1984, Vol. 1, pp. 1-13.

[15] Annan, C.D., Youssef, M.A. and Naggar, M.H.E., "Seismic Overstrength in Braced Frames of Modular Steel Buildings", Journal of Earthquake Engineering, 2009.

[16] Hong, S., Cho, B., Chung, K. and Moon, J., "Behavior of Framed Modular Building System with Double Skin Steel Panels", Journal of Constructional Steel Research, 2011, Vol. 67, pp. 936-46.

[17] Annan, C.D., Youssef, M.A. and Naggar, M.H.E, "Experimental Evaluation of the Seismic Performance of Modular Steel-braced Frames", Engineering Structures, 2009.

[18] Annan, C.D., Youssef, M.A. and Naggar, M.H.E., Seismic Vulnerability Assessment of Modular Steel Buildings", Journal of Earthquake Engineering, 2009.

[19] Lawson, P.M., Grubb, P.J., Byfield, M.P. and Popo-Ola, S.O., "Robustness of Light Steel Frames and Modular Construction", Proceedings of the ICE - Structures and Buildings, 2008, Vol. 161, pp. 3-16.

[20] Lei, M., "Research on Joint Mechanical Behavior of Container Architecture [Master]. Shang Hai: Tongji University, 2015.

[21] Eyrolles, P., Regles de calcul des Constructions en acier CM66.1975. 